Article

\title{
Coupled Thermo-Hydro-Mechanical-Chemical Modeling of Water Leak-Off Process during Hydraulic Fracturing in Shale Gas Reservoirs
}

\author{
Fei Wang *, Baoman Li, Yichi Zhang and Shicheng Zhang \\ Department of Petroleum Engineering, China University of Petroleum, Beijing 102200, China; \\ 2015212188@student.cup.edu.cn (B.L.); 2015212615@student.cup.edu.cn (Y.Z.); zhangsc@cup.edu.cn (S.Z.) \\ * Correspondence: wangfei@cup.edu.cn
}

Received: 9 September 2017; Accepted: 21 November 2017; Published: 24 November 2017

\begin{abstract}
The water leak-off during hydraulic fracturing in shale gas reservoirs is a complicated transport behavior involving thermal $(\mathrm{T})$, hydrodynamic $(\mathrm{H})$, mechanical $(\mathrm{M})$ and chemical $(\mathrm{C})$ processes. Although many leak-off models have been published, none of the models fully coupled the transient fluid flow modeling with heat transfer, chemical-potential equilibrium and natural-fracture dilation phenomena. In this paper, a coupled thermo-hydro-mechanical-chemical (THMC) model based on non-equilibrium thermodynamics, hydrodynamics, thermo-poroelastic rock mechanics, and non-isothermal chemical-potential equations is presented to simulate the water leak-off process in shale gas reservoirs. The THMC model takes into account a triple-porosity medium, which includes hydraulic fractures, natural fractures and shale matrix. The leak-off simulation with the THMC model involves all the important processes in this triple-porosity medium, including: (1) water transport driven by hydraulic, capillary, chemical and thermal osmotic convections; (2) gas transport induced by both hydraulic pressure driven convection and adsorption; (3) heat transport driven by thermal convection and conduction; and (4) natural-fracture dilation considered as a thermo-poroelastic rock deformation. The fluid and heat transport, coupled with rock deformation, are described by a set of partial differential equations resulting from the conservation of mass, momentum, and energy. The semi-implicit finite-difference algorithm is proposed to solve these equations. The evolution of pressure, temperature, saturation and salinity profiles of hydraulic fractures, natural fractures and matrix is calculated, revealing the multi-field coupled water leak-off process in shale gas reservoirs. The influences of hydraulic pressure, natural-fracture dilation, chemical osmosis and thermal osmosis on water leak-off are investigated. Results from this study are expected to provide a better understanding of the predominant leak-off mechanisms for slickwater fracturing-fluids in hydraulically fractured shale gas reservoirs.
\end{abstract}

Keywords: shale gas; water leak-off; thermo-hydro-mechanical-chemical model; multi-field coupling; numerical simulation

\section{Introduction}

In recent decades, shale gas development in North America has become very successful, which is mainly attributed to technology advancement of horizontal drilling and massive hydraulic fracturing. A large volume of slickwater, as a typical fracturing-fluid, is pumped downhole during hydraulic fracturing operations, however, the water flowback ratio is usually small during the cleanup process $[1,2]$. Many researchers suggest that the low flowback ratio is mainly due to the water leaking into the matrix [3-7]. Other researchers consider that water trapped in the fracture network is another main reason for the low flowback ratio [8-10]. In particular, the water leak-off can be attributed to five mechanisms, i.e., hydraulic pressure, natural-fracture dilation, capillarity, chemical osmosis and thermal osmosis during the treatment of hydraulic fracturing. 
Hydraulic pressure is considered to be the major mechanism for the water leak-off during the hydraulic fracturing, which creates a strong pressure difference between the bottom-hole and the matrix, further causing water leak-off from the hydraulic fracture to the matrix. Some classic pressure dependent leak-off models have been developed for decades for simulation of the hydraulic fracturing in conventional reservoirs [11-14]. Then, with the development of unconventional reservoirs, spontaneous capillary imbibition is widely considered to be an important mechanism for water leak-off especially in water-wet low permeability reservoir formation. Many researchers have conducted studies on the capillarity in shales [3,15-17]. Shear reactivation of natural fractures in shale gas reservoirs is likely to be the main deformation mechanism during hydraulic fracturing operations [18]. Weng et al. [19] believe that natural fracture dilates due to low effective normal stress and the aperture creates hydraulic conductivity during the pumping of hydraulic fracturing. After reactivation of the natural fracture, even when pumping ceases and the normal load along the fault is positive, the hydraulic aperture can be increased because small-scale asperities along the surface will not perfectly match. Thus, the natural fracture may remain partially open [20].

As a clay-rich sediment, shale contains an amount of formation brine, and the formation brine of shale has extremely high salinity, reaching up to $280,000 \mathrm{ppm}$ resulting from its tectonic compaction process and hydrogen generation process [21-24]. However, the salinity of slickwater fracturing-fluids is low, approximately 1000 ppm $[25,26]$. Chemical osmosis occurs in the leak-off process of hydraulic fracturing (because two conditions are satisfied for the occurrence of chemical osmosis, i.e., clay semipermeable membrane and salinity difference on both sides of the membrane), which results in the transport of water molecules from the low-salinity side to the high-salinity side until the salt concentration reaches an equilibrium on both sides of the shale membrane [26-29]. That makes chemical osmosis a possible leak-off mechanism for the invasion of water-based fracturing-fluids in fractured shale [30-32]. Besides the salinity difference between the fracturing-fluids and shale formation brine, a temperature gradient across the shale-fluid interface exists during the hydraulic fracturing. Therefore, thermal osmosis occurs, causing the preferred transport of water molecules from the low-temperature side to the high-temperature side until the heat content reaches an equilibrium on both sides of the shale membrane [33-35].

During the hydraulic fracturing of shale gas reservoirs, coupled thermal $(\mathrm{T})$, hydrodynamic $(\mathrm{H})$, mechanical (M) and chemical (C) processes occur, causing a complicated water leak-off behavior. Specifically, once the low-temperature, high-pressure and low-salinity water contacts the shale matrix through the hydraulic fractures, both mass and energy transfer occur due to the significant temperature, pressure, saturation and salinity gradients. Although many leak-off models have been published based on laboratory experiments and numerical simulation [3,5-8,11-14,16,32,36,37], none of the models coupled the transient fluid flow modeling with natural fracture dilation, heat transfer and chemical-potential equilibrium phenomena. To investigate all of the above-mentioned mechanisms, a coupled thermo-hydro-mechanical-chemical (THMC) model, which is based on our previous multi-mechanistic multi-porosity multi-permeability (MMM) model [37] without considering heat transfer and rock deformation, is developed to simulate the fluid/heat flow during the leak-off process of hydraulic fracturing in this study. Results from this study aim to provide a better understanding of the predominant leak-off mechanisms for slickwater fracturing-fluids in shale gas reservoirs, and therefore contribute to the post-fracturing prediction and evaluation of shale gas wells. 


\section{Chemical-Potential Equilibrium Formulation}

\subsection{Derivation of Non-Isothermal Chemical Potential Difference for Different Solutions}

For a multi-component solution system, the Gibbs free energy is not only a function of temperature and pressure, but also a function of the amount of substance in each component [38]. The full differential form of Gibbs free energy is as follows:

$$
d G=-S d T+V d p+\sum_{B} \mu_{B} d n_{B}
$$

where $S, T, V$ and $p$ refer to the entropy, temperature, volume and pressure of the system, respectively; and $n_{B}$ and $\mu_{B}$ refer to the amount and chemical potential of component $\mathrm{B}$, respectively. The partial derivative of temperature and pressure by chemical potential can be derived from Equation (1):

$$
\left(\frac{\partial \mu_{B}}{\partial T}\right)_{p}=-S_{B, m},\left(\frac{\partial \mu_{B}}{\partial p}\right)_{T}=V_{B, m}
$$

where $V_{B, m}$ and $S_{B, m}$ refer to the partial molar volume and partial molar entropy of component B, respectively. From Equation (2), the differential formula for the chemical potential of component $B$ is also represented as [39]:

$$
d \mu_{B}=-S_{B, m} d T+V_{B, m} d p
$$

The chemical potential of component $B$ can be derived from the direct integration of Equation (3):

$$
\int_{\mu^{\Theta}}^{\mu} d \mu_{B}=\int_{T^{\Theta}}^{T}-S_{B, m} d T+\int_{p^{\Theta}}^{p} V_{B, m} d p
$$

where $\mu^{\Theta}, T^{\Theta}$ and $p^{\Theta}$ denote the standard chemical potential, standard temperature and standard pressure, respectively.

If $S_{B, m}$ and $V_{B, m}$ do not change with temperature and pressure, then Equation (4) can be simplified as:

$$
\mu_{B}=\mu_{B}^{\Theta}-S_{B, m}\left(T-T^{\Theta}\right)+V_{B, m}\left(p-p^{\Theta}\right)
$$

If solution $B$ is an ideal solution, then the chemical potential of solution B can also be expressed as:

$$
\mu_{B}(T, p, a q)=\mu_{B}(T, p, l)+R T \ln x_{B}
$$

where $\mu_{B}(T, p, a q)$ represents the chemical potential of component B in the solution; $a q$ represents the solution system; $\mu_{B}(T, p, l)$ represents the chemical potential of the pure solution; $R$ represents the ideal gas constant; and $x_{B}$ represents the molar fraction of the water molecule in solution $\mathrm{B}$.

The chemical potential difference of component $B$ under different pressure, temperature and concentration conditions is derived by combining Equations (5) and (6):

$$
\begin{aligned}
& \Delta \mu_{B}=\mu_{B}\left(T_{1}, p_{1}, x_{1}, a q\right)-\mu_{B}\left(T_{2}, P_{2}, x_{2}, a q\right)=\left[\mu_{B}\left(T_{1}, p_{1}, l\right)+R T_{1} \ln x_{1}\right]-\left[\mu_{B}\left(T_{2}, p_{2}, l\right)+R T_{2} \ln x_{2}\right] \\
& =\left[\mu_{B}^{\Theta}-S_{B, m}\left(T_{1}-T^{\Theta}\right)+V_{B, m}\left(p_{1}-p^{\Theta}\right)\right]-\left[\mu_{B}^{\Theta}-S_{B, m}\left(T_{2}-T^{\Theta}\right)+V_{B, m}\left(p_{2}-p^{\Theta}\right)\right]+R T_{1} \ln x_{1}-R T_{2} \ln x_{2} \\
& =V_{B, m}\left(p_{1}-p_{2}\right)-S_{B, m}\left(T_{1}-T_{2}\right)+R T_{1} \ln x_{1}-R T_{2} \ln x_{2}
\end{aligned}
$$

where the subscripts 1 and 2 identify two different solutions.

\subsection{Non-Isothermal Chemical Potential Difference between the Slickwater and Formation Brine}

Once the low-temperature, high-pressure and low-salinity slickwater fracturing-fluid enters the shale matrix, which contains high-temperature, low-pressure and high-salinity brine, during the hydraulic fracturing of shale gas reservoirs, the chemical-potential equilibrium phenomena occur. 
Based on Equation (7), the non-isothermal chemical-potential difference of water between the formation brine and fracturing-fluid can be expressed by

$$
\Delta \mu_{w}=\mu_{w}^{f}-\mu_{w}^{m}=V_{w, m}\left(p_{f}-p_{m}\right)-S_{w, m}\left(T_{f}-T_{m}\right)+\left(R T_{f} \ln x_{f}-R T_{m} \ln x_{m}\right)
$$

where $\mu_{w}^{f}$ and $\mu_{w}^{m}$ refer to the chemical potential of the fracturing-fluid and the formation brine in the matrix, respectively; $V_{w, m}$ and $S_{w, m}$ refer to the partial molar volume and partial molar entropy of water, respectively; $p_{f}$ and $p_{m}$ refer to the pore pressures in the fracture and the matrix, respectively; $T_{f}$ and $T_{m}$ refer to the temperature in the fracture and matrix, respectively; and $x_{f}$ and $x_{m}$ refer to the molar fraction of water molecule in the fracturing-fluid and the formation brine, respectively.

If Equation (8) is rearranged as follows, the left term $\Delta \mu / V$ has a dimensional pressure.

$$
\frac{\Delta \mu_{w}}{V_{w, m}}=\frac{\mu_{w}^{f}-\mu_{w}^{m}}{V_{w, m}}=\left(p_{f}-p_{m}\right)-\frac{S_{w, m}}{V_{w, m}}\left(T_{f}-T_{m}\right)+\frac{R}{V_{w, m}}\left(T_{f} \ln x_{f}-T_{m} \ln x_{m}\right)
$$

where the first term on the right side refers to the pressure difference of the two solution systems; the second term on the right side refers to the temperature-difference-induced chemical-potential difference; and the third term on the right side refers to the concentration-difference-induced chemical-potential difference. All these three terms on the right side of Equation (9) have the dimensional pressure, and they all can be driving forces of water leak-off.

Specifically, the first driving force is the pressure difference, $p_{f}-p_{m}$, that is, the conventional viscous force heavily depending on the hydraulic pressure of the fracturing treatment. $R\left(T_{f} \ln x_{f}-T_{m} \ln x_{m}\right) / V_{w, m}$ refers to the chemical-osmotic pressure caused by the difference in the molar fraction of water, that is, the force that drives water to flow from the low-salinity side to the high-salinity side. $S_{w, m}\left(T_{f}-T_{m}\right) / V_{w, m}$ refers to the thermo-osmotic pressure caused by the difference of water temperature, that is, the force that drives water to flow from the low-temperature side to the high-temperature side.

Considering the non-idealization of shale semipermeable membrane [40-43], the pressure driving the water from fracture to matrix can be expressed as:

$$
\frac{\Delta \mu_{w}}{V_{w, m}}=\frac{\mu_{w}^{f}-\mu_{w}^{m}}{V_{w, m}}=\left(p_{f}-p_{m}\right)-\lambda \frac{S_{w, m}}{V_{w, m}}\left(T_{f}-T_{m}\right)+\lambda \frac{R}{V_{w, m}}\left(T_{f} \ln x_{f}-T_{m} \ln x_{m}\right)
$$

Because only the osmosis process relates to the shale semipermeable membrane, the membrane efficiency $\lambda$ is added to the last two terms (thermal and chemical osmosis terms).

\section{Mean-Stress Geomechanical Formulation}

The mean-stress geomechanical formulation is based on the thermo-poroelasticity theory extended to the multiporosity medium. In the thermo-poroelasticity theory, the stress/strain behavior for a non-isothermal material is expressed as [44]:

$$
\sigma=\xi \operatorname{tr}(\varepsilon) \mathrm{I}+2 G \varepsilon+(\delta p+3 \beta K \Delta T) \mathrm{I}
$$

where $G$ and $\xi$ refer to the shear modulus and Lamé parameter. $\delta$ and $p$ refer to the Biot's coefficient and pore pressure. $K$ and $\beta$ refer to the bulk modulus and linear thermal-expansion coefficient. $\varepsilon$ and $\sigma$ refer to the strain tensor and stress tensor. $\Delta T$ refers to the temperature difference of the thermo-poroelastic medium. 
Winterfeld and $\mathrm{Wu}$ [45] presented a generalized thermo-poroelastic formulation for the multiporosity medium by introducing a weight $\omega^{j}$ for each temperature term, as follows

$$
\sigma=2 G \varepsilon+\xi \operatorname{tr}(\varepsilon) \mathrm{I}+\left[\sum_{j}\left(\delta^{j} p^{j}+3 \beta K \omega^{j} \Delta T^{j}\right)\right] \mathrm{I}
$$

where the summation is over multiporosity continua. $\delta^{j}, p^{j}$ and $\Delta T^{j}$ refer to the generalized expression of Biot's coefficient, pore pressure and temperature difference for the multiporosity medium. $\omega^{j}$ refers to the porous continuum volume fraction. After hydraulic fracturing, a complex fracture network is generated by the interaction of hydraulic fractures and natural fractures [46,47]. Therefore, it is appropriate to divide a fractured shale reservoir into a triple-porosity system, including primary hydraulic fractures $(F)$, natural fractures $(f)$ and shale matrix $(m)$.

Two other fundamental relations in the theory of linear elasticity are the relation between the strain tensor $\varepsilon$ and the displacement vector $u$,

$$
\varepsilon=\frac{1}{2}\left(\nabla u+\nabla u^{t}\right)
$$

and the static equilibrium equation,

$$
\nabla \sigma+F_{b}=0
$$

where $F_{b}$ is the body force. Combining Equations (12)-(14) yields a multiporoelastic equation relating mean stress, pore pressures and temperatures:

$$
\nabla\left\{\frac{3(1-v)}{1+v} \nabla \sigma_{m}+F_{b}-\frac{2(1-2 v)}{1+v} \cdot \nabla\left[\sum_{j}\left(\delta^{j} p^{j}+3 \beta K \omega^{j} T^{j}\right)\right]\right\}=0
$$

where $v$ refers to the Poisson's ratio. $\sigma_{m}$ is the mean stress, the average of the normal stress-tensor components.

Rock porosity is correlated to the stress, a general definition of which was given by Biot and Willis [48]:

$$
\phi^{j}=\frac{\phi_{o}^{j}-\varepsilon_{v}}{1-\varepsilon_{v}}
$$

where $\phi^{j}$ refers to the porosity of hydraulic fractures, natural fractures and matrix, when the superscript $j$ refers to $F, f$ and $m$, respectively.

\section{Fluid and Heat Flow Formulation}

The following fluid and heat flow equations for water and gas in hydraulically fractured shale reservoirs are the extension of "MMM model", which was developed by Wang et al. [37] for the iso-thermal fracturing-fluid leak-off simulation, but without considering the phenomena of water thermal osmosis and rock thermal poroelastic deformation. In this study, the THMC leak-off model is considered as a triple-porosity model including three interconnected domains of hydraulic fractures $(F)$, natural fractures $(f)$ and matrix $(m)$. In the following mathematical model, the subscript $l$ refers to $w$ or $g$, which represents water or gas. Superscript $F, f$ and $m$ represent the hydraulic fracture, natural fracture and matrix, respectively.

(1) Fluid Flow in the Hydraulic Fracture

$$
\frac{\partial\left(\rho_{l} \phi^{F} S_{l}^{F}\right)}{\partial t}=-\nabla\left(\rho_{l} v_{l}^{F}\right)-q_{l}^{F f}-q_{l}^{F W}
$$


where $\rho_{l}$ is the fluid density $\left(\mathrm{g} / \mathrm{cm}^{3}\right) ; \phi^{F}$ is the porosity of hydraulic fractures(dimensionless); $S_{l}^{F}$ is the fluid saturation in the hydraulic fracture (dimensionless); $q_{l}^{F W}$ is the flowback rate $\left(\mathrm{g} / \mathrm{cm}^{3} \cdot \mathrm{s}\right) ;$ and $v_{l}^{F}$ is the fluid flow velocity in hydraulic fractures $(\mathrm{cm} / \mathrm{s})$, which is defined as [49]

$$
-\nabla p_{l}^{F}=\frac{\eta_{l}}{k^{F} k_{r l}^{F}} v_{l}^{F}+\beta \rho_{l}\left(v_{l}^{F}\right)^{2}
$$

where $k^{F}$ is the permeability of hydraulic fractures $\left(\mu \mathrm{m}^{2}\right) ; k_{r l}^{F}$ is the relative permeability in hydraulic fractures (dimensionless); $\eta_{l}$ is the fluid viscosity $(\mathrm{mPa} \cdot \mathrm{s}) ; p_{l}^{F}$ is the fluid pressure in hydraulic fractures $\left(10^{-1} \mathrm{MPa}\right) ;$ and $\beta$ is the non-Darcy coefficient (dimensionless).

In Equation (17), $q_{l}^{F W}$ and $q_{l}^{F f}$ refer to the fluid fluxes between the hydraulic fracture and the wellbore and the natural fracture $\left(\mathrm{g} / \mathrm{cm}^{3} \cdot \mathrm{s}\right)$, respectively, which are defined below

$$
\begin{aligned}
q_{l}^{F W} & =\frac{\alpha_{3} \rho_{w} k^{F} k_{r l}\left(p_{l}^{F}-p_{w f}\right)}{\eta_{l} B_{l}} \\
q_{l}^{F f} & =\frac{\alpha_{1} \rho_{l} k^{F} k_{r l}^{F}}{\eta_{l}}\left(p_{l}^{F}-p_{l}^{f}\right)
\end{aligned}
$$

where $p_{l}^{f}$ and $p_{w f}$ denote the fluid pressure in natural fractures and flowing pressure at the bottom-hole $\left(10^{-1} \mathrm{MPa}\right) ; \alpha_{1}$ and $\alpha_{3}$ denote the shape factors between the hydraulic fracture and the natural fracture and the wellbore $\left(\mathrm{cm}^{-2}\right)$, respectively, which are decided as presented in Wang et al. [37] and Bian et al. [50]; and $B_{l}$ denotes the fluid volume factor (dimensionless).

(2) Heat Flow in the Hydraulic Fracture

$$
\begin{aligned}
& \frac{\partial\left[\left(1-\phi^{F}\right) C_{r} \rho_{r} T^{F}+\phi C_{w} \rho_{w} T^{F}\right]}{\partial t}=\nabla\left\{\left[\left(1-\phi^{F}\right) C_{r} \rho_{r}+\phi^{F} C_{w} \rho_{w}\right] D_{e} \cdot \nabla T^{F}\right\} \\
& +\nabla\left[\phi^{F} C_{w} \rho_{w} T^{F} \frac{k^{F}}{\eta_{w}}\left(\nabla p_{w}^{F}\right)\right]-H_{w}^{F f}+\hat{H}_{w}
\end{aligned}
$$

where $\rho_{r}$ and $\rho_{w}$ refer to the rock and fluid density $\left(\mathrm{g} / \mathrm{cm}^{3}\right)$, respectively; $C_{r}$ and $C_{w}$ refer to the heat capacity of rock and fluid $(\mathrm{J} /(\mathrm{g} \cdot \mathrm{K}))$, respectively; and $D_{e}$ refers to the thermal diffusivity coefficient $\left(\mathrm{cm}^{2} / \mathrm{s}\right)$. The term on the left side refers to the energy storage. The first term on the right side refers to the heat conduction. The second term on the right side refers to the thermal convection. $H_{w}^{F f}$ and $\hat{H}_{w}$ refer to the convective energy flux terms between the hydraulic fracture and natural fracture and wellbore $\left(\mathrm{J} /\left(\mathrm{cm}^{3} \cdot \mathrm{s}\right)\right)$, which are defined below:

$$
\begin{gathered}
H^{F f}=\phi^{F} \cdot C_{w} \cdot q_{w}^{F f} \cdot T^{F} \\
\hat{H}_{w}=\phi^{F} \cdot C_{w} \cdot \hat{q}_{w} \cdot \hat{T}
\end{gathered}
$$

where $\hat{T}$ and $T^{F}$ refer to the fluid temperature in the wellbore and hydraulic fractures (K), respectively.

(3) Fluid Flow in the Natural Fracture

$$
\frac{\partial\left(\rho_{l} \phi^{f} S_{l}^{f}\right)}{\partial t}=-\nabla\left(\rho_{l} v_{l}^{f}\right)+q_{l}^{F f}-q_{l}^{f m}
$$

where $\phi^{f}$ and $S_{l}^{f}$ are the porosity and fluid saturation in natural fractures (dimensionless), respectively; and $v_{l}^{f}$ is the fluid flow velocity in natural fractures $(\mathrm{cm} / \mathrm{s})$, which is defined as Darcy law:

$$
v_{l}^{f}=-\frac{k^{f} k_{r l}^{f}}{\eta_{l}} \nabla\left(p_{l}^{f}+p_{c, l}^{f}\right)
$$


where $k^{f}, k_{r l}^{f}, p_{l}^{f}$ and $p_{c, l}^{f}$ refer to the permeability, relative permeability, fluid pressure and capillary pressure in the natural fractures, respectively.

In Equation (21), $q_{l}^{f m}$ denotes the fluid flux between the natural fracture and matrix $\left(\mathrm{g} / \mathrm{cm}^{3} \cdot \mathrm{s}\right)$, which is defined as

$$
q_{l}^{f m}=\frac{\alpha_{2} \rho_{l} k^{f} k_{r l}^{f}}{\eta_{l}}\left(\frac{\mu_{w}^{f}-\mu_{w}^{m}}{V_{w, m}}\right)
$$

where $\alpha_{2}$ is described by the Kazemi model to represent the shape factor between the natural fracture and matrix [51]; $\left(\mu_{w}^{f}-\mu_{w}^{m}\right) / V_{w, m}$ represents the non-isothermal chemical potential difference $\left(10^{-1} \mathrm{MPa}\right)$, which is only for water phase, described by Equation (10).

(4) Heat Flow in the Natural Fracture

$$
\begin{aligned}
& \frac{\partial\left[\left(1-\phi^{f}\right) C_{r} \rho_{r} T^{f}+\phi C_{w} \rho_{w} T^{f}\right]}{\partial t}=\nabla\left\{\left[\left(1-\phi^{f}\right) C_{r} \rho_{r}+\phi^{f} C_{w} \rho_{w}\right] D_{e} \cdot \nabla T^{f}\right\} \\
& +\nabla\left[\phi^{f} C_{w} \rho_{w} T^{f} \frac{k^{f}}{\eta_{w}}\left(\nabla p_{w}^{f}\right)\right]+H_{w}^{F f}-H_{w}^{f m}
\end{aligned}
$$

where $H_{w}^{f m}$ denotes the convective energy flux terms between the natural fracture and matrix $\left(\mathrm{J} /\left(\mathrm{cm}^{3} \cdot \mathrm{s}\right)\right)$, which is defined below

$$
H^{f m}=\phi^{f} \cdot C_{w} \cdot q_{w}^{f m} \cdot T^{f}
$$

where $T^{f}$ denotes the fluid temperature in the natural fractures $(\mathrm{K})$.

(5) Fluid Flow in the Matrix

$$
\frac{\partial\left(\rho_{l} \phi^{m} S_{l}^{m}+m_{g}\right)}{\partial t}=-\nabla\left(\rho_{l} v_{l}^{m}\right)+q_{l}^{f m}
$$

where $\phi^{m}$ and $S_{l}^{m}$ refer to the porosity and fluid saturation in the matrix, respectively; and $v_{l}^{m}$ refers to the fluid flow velocity $(\mathrm{cm} / \mathrm{s})$, which is defined as Darcy law:

$$
v_{l}^{m}=-\frac{k^{m} k_{r l}^{m}}{\eta_{l}} \nabla\left(p_{l}^{m}+p_{c, l}^{m}+p_{\pi}^{m}\right)=-\frac{k^{m} k_{r l}^{m}}{\eta_{l}} \nabla\left(p_{l}^{m}+p_{c, l}^{m}+\lambda \frac{R T^{m}}{V_{w, m}} \ln x^{m}-\lambda \frac{S_{w, m}}{V_{w, m}} T^{m}\right)
$$

where $k^{m}$ and $k_{r l}^{m}$ are the permeability and relative permeability in the matrix, respectively; and $p_{\pi}^{m}$ is the osmotic pressure in the matrix $\left(10^{-1} \mathrm{MPa}\right)$, which is only for water phase.

The mass of adsorbed gas in formation volume $m_{g}$ in Equation (29) is derived from the Langmuir isotherm [52]:

$$
m_{g}=\rho_{r} \rho_{g s c} S_{k} V_{L} \frac{p_{g}^{m}}{p_{g}^{m}+p_{L}}
$$

where $\rho_{r}$ and $\rho_{g s c}$ are the source rock density and gas density at standard condition $\left(\mathrm{g} / \mathrm{cm}^{3}\right) ; S_{k}$ is the volume proportion of source rock; and $V_{L}$ and $p_{L}$ are the Langmuir's volume $\left(\mathrm{cm}^{3} / \mathrm{g}\right)$ and pressure $\left(10^{-1} \mathrm{MPa}\right)$, respectively.

(6) Heat Flow in the Matrix

$$
\begin{aligned}
& \frac{\partial\left[\left(1-\phi^{m}\right) C_{r} \rho_{r} T^{m}+\phi^{m} C_{w} \rho_{w} T^{m}\right]}{\partial t}=\nabla\left\{\left[\left(1-\phi^{m}\right) C_{r} \rho_{r}+\phi^{m} C_{w} \rho_{w}\right] D_{e} \cdot \nabla T^{m}\right\} \\
& +\nabla\left\{\phi^{m} C_{w} \rho_{w} T^{m} \frac{k^{m}}{\eta_{w}}\left[\nabla\left(p^{m}+\lambda \frac{R T^{m}}{V_{w}} \ln x^{m}-\lambda \frac{S_{w}}{V_{w}} T^{m}\right)\right]\right\}+H_{w}^{f m}
\end{aligned}
$$

where $T^{m}$ refers to the fluid temperature in the matrix $(\mathrm{K})$. 


\section{Coupling and Solution of Simulator Equations}

Based on the above formulations, the following assumptions and considerations are made: (1) the effect of stress-dependent natural-fracture dilation is considered; (2) the effect of capillarity is considered; (3) the effect of chemical osmosis is considered;(4) the effect of thermal osmosis is considered; (5) the effect of gas adsorption is considered; (6) heat conduction and thermal convection of the fluid through the porous rock are considered; (7) a two-dimensional flow (including conduction and convection) within the hydraulic fractures, natural fractures and matrix is considered; (8) the effect of gravity is disregarded; and (9) fluid (including water and gas) is slightly compressible.

We couple fluid and heat flow to non-isothermal chemical-potential equilibrium and geomechanics by solving Equations (10) and (16) along with the mass and energy conservation equations (Equations (17), (21), (24), (27), (29) and (32)) from the fluid and heat flow formulation in hydraulic fractures, natural fractures and matrix. The fluid and heat flow, chemical-potential equilibrium and geomechanical equations are discretized in space using the finite-difference method. A semi-implicit algorithm is used to solve the nonlinear equations after discretization. The Newton-Raphson method is used for iterative solution. In this method, the simulation domain is subdivided into grid blocks in three systems $(F, f$ and $m)$. The grid schematic diagram of the concept THMC model is shown in Figure 1. In the THMC model, the hydraulic fractures are idealized propped planar fractures, which are directly connected to the horizontal wellbore. The natural fractures and inorganic matrix are designed into an internally connected parallel system. The natural-fracture density can be numerically represented by the shape factor between the natural fracture and matrix [53]. The correlation between natural-fracture density $\left(n_{f}\right)$ and the shape factor $(\alpha)$ proposed by Yan et al. [54] is applied to our THMC model. The horizontal wellbore and disconnected organic matter are treated as sink-source terms for the convenience of modeling.
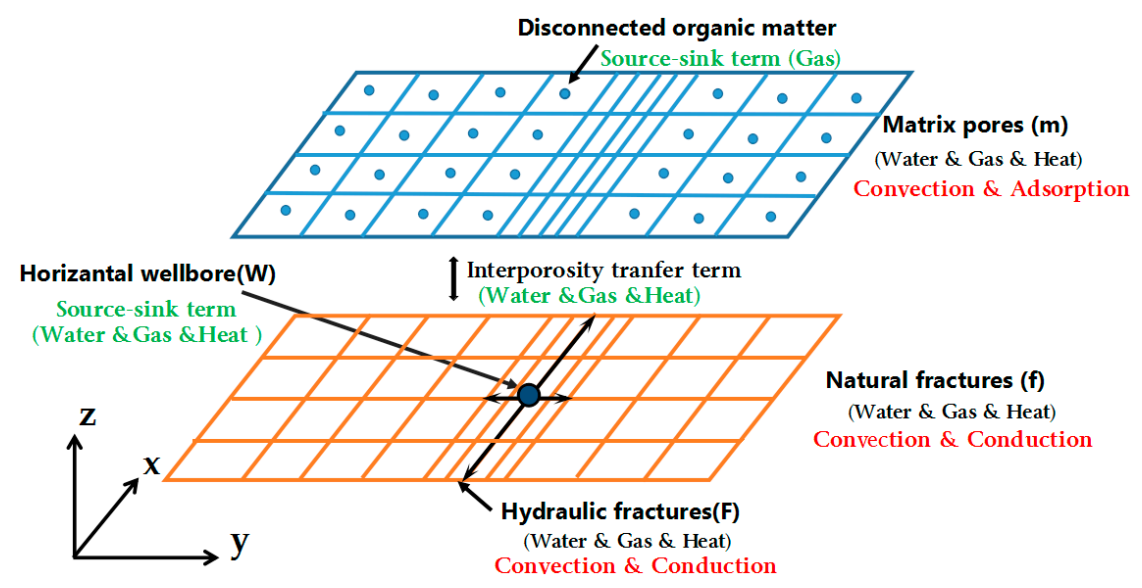

Figure 1. Grid schematic diagram of the thermo-hydro-mechanical-chemical (THMC) model.

A simulator is developed to achieve numerical simulation with the proposed THMC model. Figure 2 presents the flow chart of our simulator, which is composed of six steps. (1) Discretize the nonlinear equations; (2) Initialize the temperature, pressure, saturation, salinity and mean stress in hydraulic fractures, natural fractures and matrix; (3) Compute the phase transmissibility $\left(\rho_{l} k^{j} k_{r l} / \eta_{l}\right)$ at each time step; (4) Solve the discrete equation system according to initial and boundary conditions to update variables $\left(T^{j}, P_{l}^{j}, S_{l}^{j}, C^{j}, \sigma_{m}\right.$, and $\left.\rho_{l}\right)$; (5) If the equation residuals and primary variables converge, solve the geomechanical equations and updating the stress-dependent porosity $\left(\varphi^{j}\right)$. Otherwise, cycle back to compute the phase transmissibility until it converges at current time step; (6) If the set-up time has not been reached, proceed to compute the phase transmissibility at next time step with the updated values $\left(T^{j}, P_{l}^{j}, S_{l}^{j}, C^{j}, \sigma_{m}, \rho_{l}\right.$, and $\left.\varphi^{j}\right)$. Otherwise, end the program and output the results of each time step. 


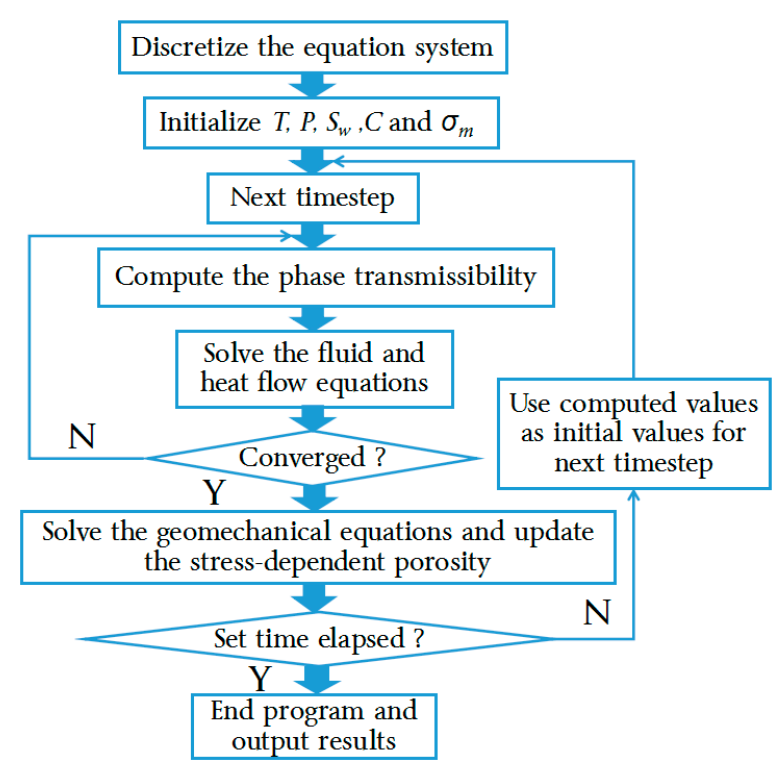

Figure 2. Simulator flow chart.

\section{Numerical Simulation Cases}

\subsection{Simulation Model Description}

Numerical simulation is performed using the developed numerical simulator to model the leak-off behavior of water during the hydraulic fracturing. The geometry of the simulated shale gas reservoir is $1200 \mathrm{~m} \times 600 \mathrm{~m} \times 42 \mathrm{~m}$. A horizontal well with a lateral length of $1180 \mathrm{~m}$ is located in the center of the reservoir. One hundred twenty transverse fractures with the same half-length of $140 \mathrm{~m}$ (completed by a thirty-stage hydraulic fracturing treatment) are generated along the horizontal wellbore. We assume the hydraulic fractures are evenly spaced. The inputs of the reservoir, fracture, fluid and heat properties $[35,36,55-58]$ are given in Table 1 .

The relative permeability of gas-water in $F, f$ and $m$ are set according to a previous simulation case [37]. The empirical equation proposed by Gdanski et al. [59] is used to calculate the capillary pressure curves. The slickwater pumping is simulated as a process of water injection. The simulation is initialized by continuously injecting water for $1.5 \mathrm{~h}$ through the horizontal wellbore with a bottom-hole flowing pressure of $55 \mathrm{MPa}$ and following a well shut-in of $24 \mathrm{~h}$.

Table 1. Model inputs of the reservoir, fracture, fluid and heat properties.

\begin{tabular}{|c|c|c|c|}
\hline Parameter, Symbol & Value & Parameter, Symbol & Value \\
\hline Initial mean stress, $\sigma_{m i}$ & $52 \mathrm{MPa}$ & Initial porosity, $\varphi_{i}{ }^{F}, \varphi_{i}^{f}, \varphi_{i}^{m}$ & $0.15,0.015,0.05$ \\
\hline Initial reservoirpressure, $p_{i}$ & $25 \mathrm{MPa}$ & Stress-dependent coefficient, $c_{k}{ }^{F}, c_{k}{ }^{f}, c_{k}{ }^{m}$ & $0.05,0.12,10^{-5} \mathrm{MPa}^{-1}$ \\
\hline Reservoir temperature, $T$ & $323 \mathrm{~K}$ & Initial water saturation, $S_{w i}{ }^{F}, S_{w i} f, S_{w i}{ }^{m}$ & $0.2,0.2,0.2$ \\
\hline Poisson's ratio, $v$ & 0.2 & Irreducible water saturation, $S_{w, i r r} F, S_{w, i r r} f, S_{w, i r r} m$ & $0.1,0.2,0.6$ \\
\hline Water density, $\rho_{w}$ & $1000 \mathrm{~kg} / \mathrm{m}^{3}$ & Permeability, $k^{F}, k^{f}, k^{m}$ & $100 \mathrm{md}, 10,000 \mathrm{nd}, 100 \mathrm{nd}$ \\
\hline Water viscosity, $\eta_{w}$ & $0.8 \mathrm{mPa} \cdot \mathrm{s}$ & Injected water salinity, $C^{i n j}$ & $1000 \mathrm{ppm}$ \\
\hline Water compressibility, $c_{w}$ & $4 \times 10^{-4} \mathrm{MPa}^{-1}$ & Biot coefficient, $\beta^{F}, \beta^{f}, \beta^{m}$ & $0.76,0.06,0.18$ \\
\hline Natural fracture density, $n_{\mathrm{f}}$ & 5 & Initial salinity, $C_{i}{ }^{F}, C_{i}^{\mathrm{f}}, C_{i}^{m}$ & $1000,10,000,280,000 \mathrm{ppm}$ \\
\hline Membrane efficiency, $\lambda$ & 0.06 & Volume proportion of source rock, $S_{\mathrm{k}}$ & 0.1 \\
\hline Langmuir's pressure, $p_{\mathrm{L}}$ & $5.8 \mathrm{MPa}$ & Ideal gas constant, $R$ & $8.314 \mathrm{~J} /(\mathrm{mol} \cdot \mathrm{K})$ \\
\hline Rock density, $\rho_{r}$ & $2560 \mathrm{~kg} / \mathrm{m}^{3}$ & Langmuir's volume, $V_{\mathrm{L}}$ & $3.32 \times 10^{-3} \mathrm{~m}^{3} / \mathrm{kg}$ \\
\hline Gas compressibility, $c_{g}$ & $0.03 \mathrm{MPa}^{-1}$ & Gas density at standard condition, $\rho_{\mathrm{gsc}}$ & $0.77 \mathrm{~kg} / \mathrm{m}^{3}$ \\
\hline Gas viscosity, $\eta_{\mathrm{g}}$ & $0.058 \mathrm{mPa} \cdot \mathrm{s}$ & Partial molar volume of water, $V_{w, m}$ & $18.02 \times 10^{-6} \mathrm{~m}^{3} / \mathrm{mol}$ \\
\hline Injected water temperature, $T_{f}$ & $288 \mathrm{~K}$ & Partial molar entropy of water, $S_{w, m}$ & $69.91 \mathrm{~J} /(\mathrm{mol} \cdot \mathrm{K})$ \\
\hline Heat capacity of rock, $C_{r}$ & $774 \mathrm{~J} /(\mathrm{kg} \cdot \mathrm{K})$ & Heat capacity of fluid, $C_{w}$ & $4200 \mathrm{~J} /(\mathrm{kg} \cdot \mathrm{K})$ \\
\hline Solid bulk modulus $K_{r}$ & $11.44 \mathrm{GPa}$ & Thermal diffusivity coefficient, $D_{e}$ & $1.6 \times 10^{-6} \mathrm{~m}^{2} / \mathrm{s}$ \\
\hline
\end{tabular}




\subsection{Basecase Simulation Results}

Figure 3 exhibitsthe evolution of pressure, temperature, saturation, and salinity profiles of the hydraulic fracture from the beginning of slickwater injection to the end of the 24-h well shut-in. The horizontal coordinate-axis $X$ represents the location along the length of the hydraulic fracture. The zero point of axis $X$ represents the location of the wellbore, also the center of the hydraulic fracture. It indicates that the pore pressure in hydraulic fractures increases quickly during the injection process, as shown in Figure 3a. After 1.5-h injection, the pore pressure at the fracture toe has increased to above 54.9 MPa from the initial $25 \mathrm{MPa}$. After the 24-h well shut-in, the pore pressure profile exhibits a constant level of approximately $27.95 \mathrm{MPa}$, which indicates that the pressure equilibrium state in the hydraulic fracture has been achieved. Figure $3 \mathrm{~b}$ indicates that the temperature in the hydraulic fracture decreases quickly during the injection process, but increases slowly during the well shut-in process. As shown in Figure 3c, the saturation profile in the hydraulic fracture also increases quickly. After 1.5-h injection, the water saturation profile has increased to above 0.92 from the initial value of 0.2. Later, the water saturation profile decreases slowly. At the end of the 24 -h shut-in, the water saturation in the hydraulic fracture has shifted down to 0.84, suggesting that the water continues leaking into the natural fractures. Figure $3 \mathrm{~d}$ indicates that, during the injection process, the salinity profile keeps at 1000 ppm, because there is no salinity difference between the pumped water and the original water in the hydraulic fractures. At the end of the 24-h well shut-in, the salinity in the hydraulic fracture has increased to approximately 1065 ppm from the initial $1000 \mathrm{ppm}$.

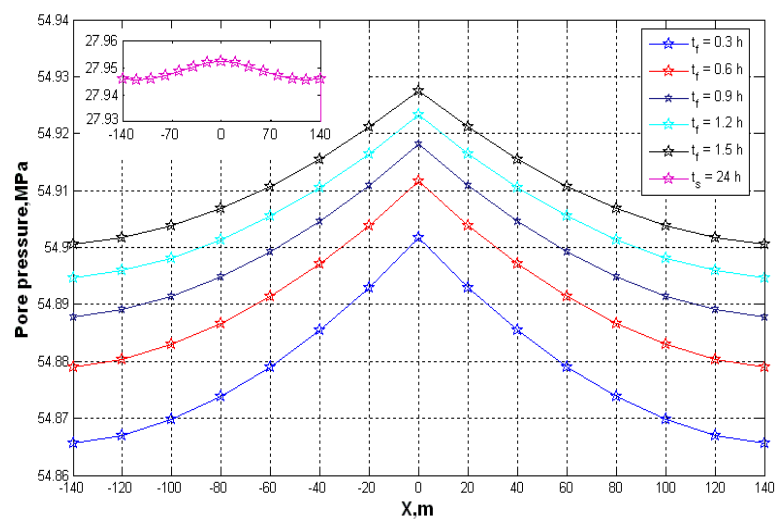

(a)

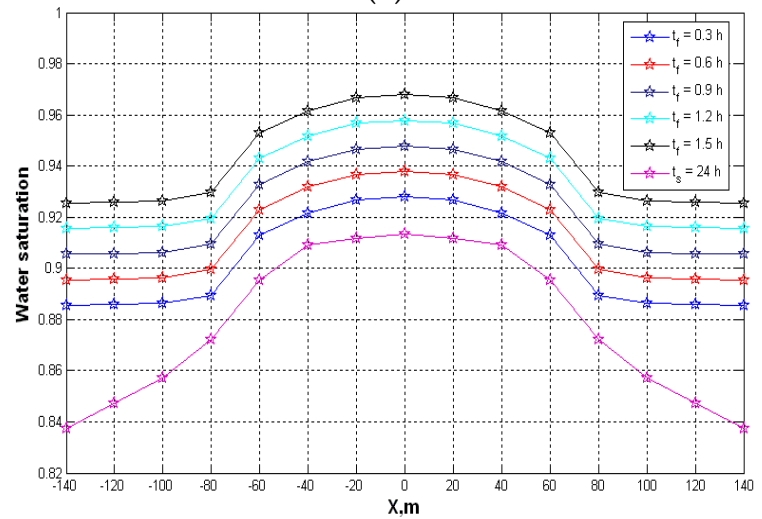

(c)

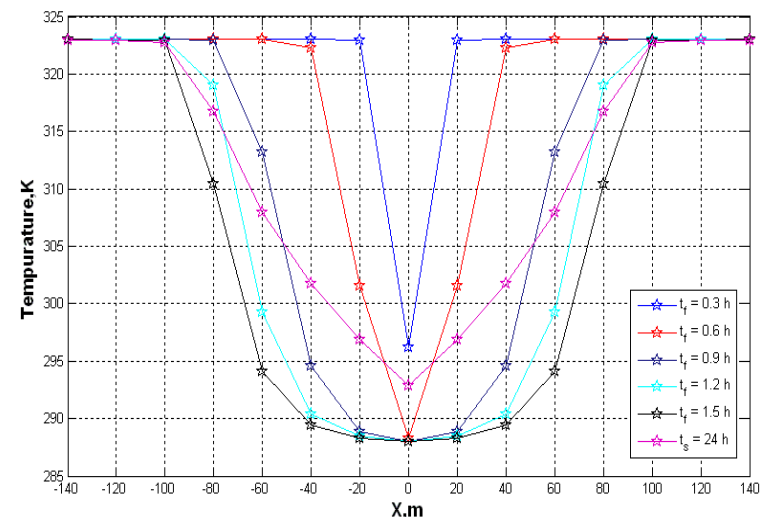

(b)

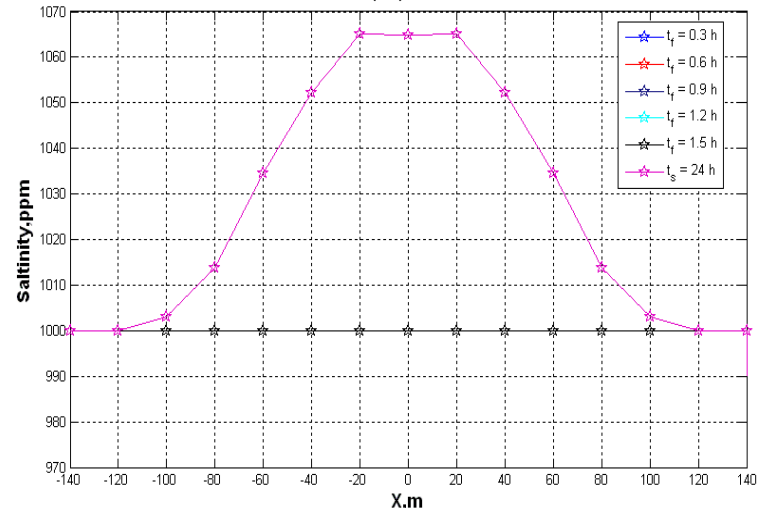

(d)

Figure 3. Results of base case in the hydraulic fracture: (a) pore-pressure profiles; (b) temperature profiles; (c) water-saturation profiles; and (d) salt-concentration profiles.

Figure 4 displays the dynamic simulation results of base case in the natural fracture. As shown in Figure $4 \mathrm{a}$, the pore pressure in the natural fracture increases quickly. After 1.5-h water injection, 
the pore pressure at the hydraulic-fracture face is increased to $48.4 \mathrm{MPa}$. During the well shut-in, the pore pressure in the natural fracture continuously decreases. At the end of the 24-h shut-in, the pore pressure at the fracture face decreases to $28.2 \mathrm{MPa}$ but the pressure transient has been reached to $4.9 \mathrm{~m}$. Figure $4 \mathrm{~b}$ indicates that the temperature in the near-hydraulic-fracture region decreases quickly during the injection process, but increases slowly during the well shut-in process. The thermal front after $24 \mathrm{~h}$ shut-in is approaching $2.8 \mathrm{~m}$. Figure $4 \mathrm{c}$, d indicates that, during the injection process, the saturation profile increases gradually and the salinity profile decreases simultaneously, suggesting that the water leak-off continues in the natural fracture. At the end of the injection, a high-water-saturation and a low-salt-concentration region surrounding the hydraulic fracture are created, respectively. The leak-off front of water is about $1.4 \mathrm{~m}$ away from the hydraulic fracture face. The high-water-saturation region grows narrow after the 24-h shut-in, indicating that the leak-off continues from the natural fractures into the matrix. Figure 5 exhibits the dynamic profiles of pressure, temperature, saturation and salinity in the matrix. Similar flow patterns can be found but all the fronts of pressure, temperature, saturation and salinity are greater than those in the natural fractures due to the extra driven force of chemical and thermal osmosis.

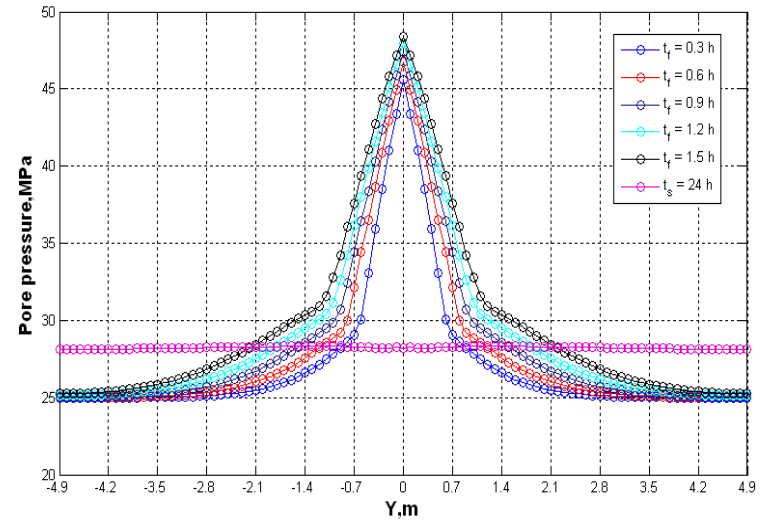

(a)

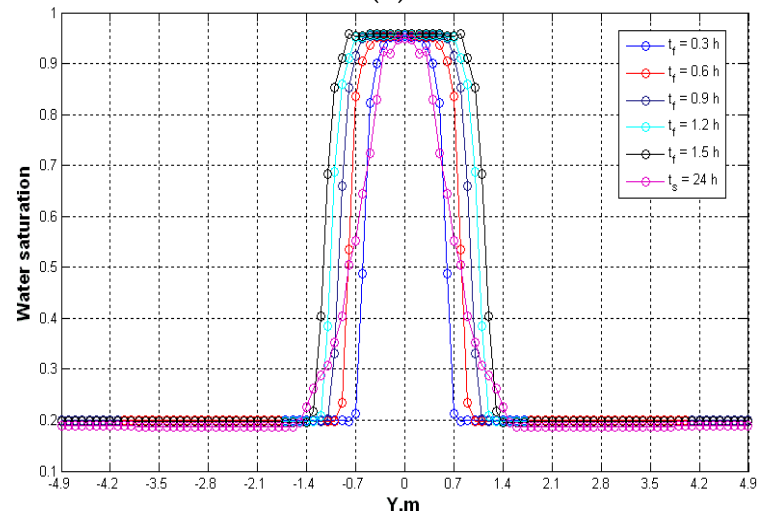

(c)

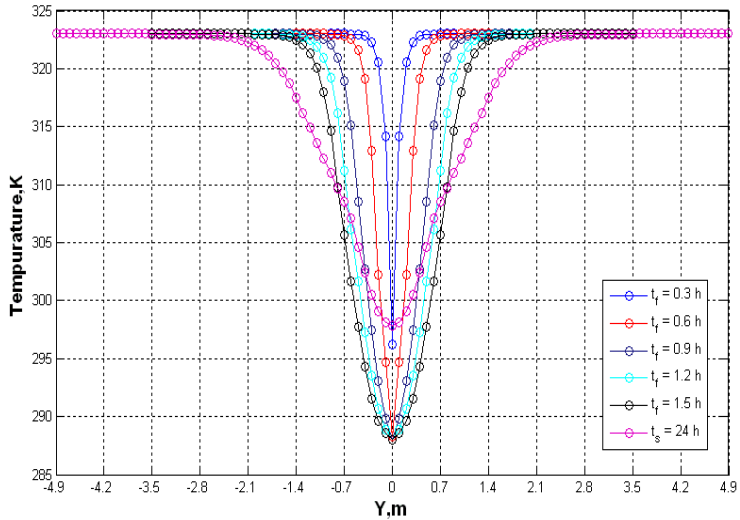

(b)

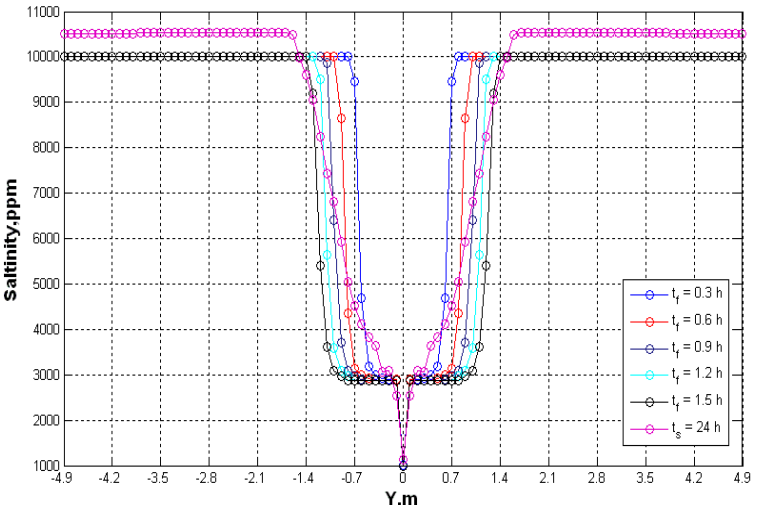

(d)

Figure 4. Results of base case in the natural fracture: (a) pore-pressure profiles; (b) temperature profiles; (c) water-saturation profiles; and (d) salt-concentration profiles. 


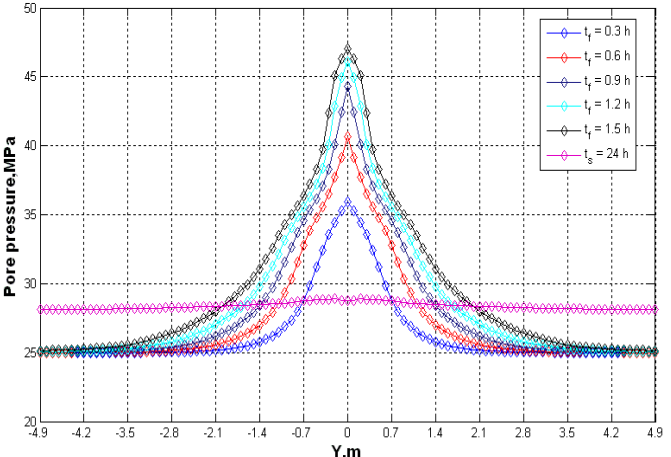

(a)

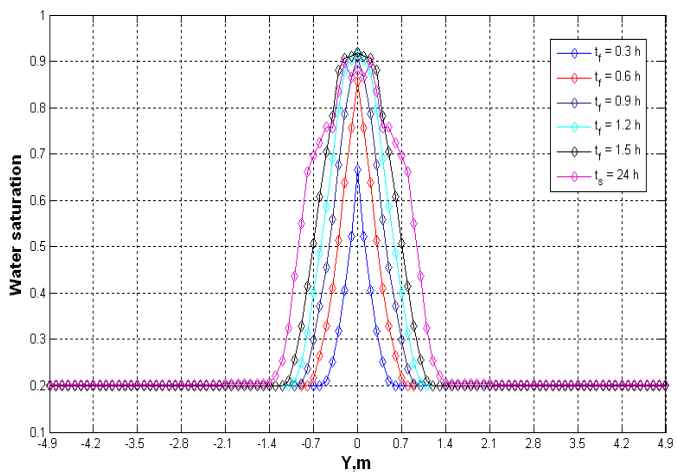

(c)

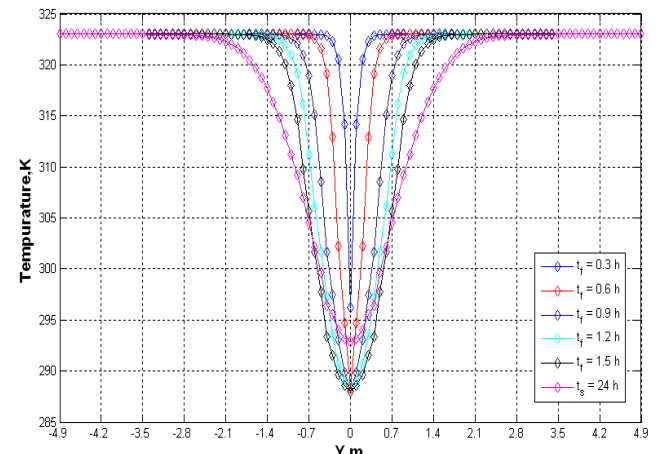

(b)

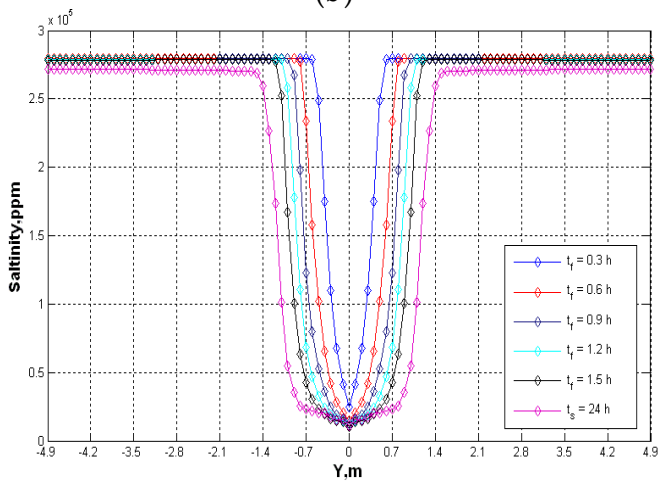

(d)

Figure 5. Results of base case in the matrix: (a) pore-pressure profiles; (b) temperature profiles; (c) water-saturation profiles; and (d) salt-concentration profiles.

Figure 6 shows the comparison of water fluxes and accumulated fluxes between the three media. As shown in Figure 6a, the water flux of $W-F$ increases initially and then decreases gradually during the water injection. The water flux of $F-f$ begins to drop when it increases to some certain extent during the water injection, and further drops quickly during the subsequent shut-in period. By contrast, the water flux of $f-m$ increases quickly during the water injection but decreases slowly during the well shut-in. The accumulated fluxes of $W-F, F-f$ and $f-m$ are presented in Figure $6 \mathrm{~b}$. After $1.5 \mathrm{~h}$ of water injection, the total injection volume of $W-F$ is $17,089 \mathrm{~m}^{3}$, of which approximately $9209 \mathrm{~m}^{3}$ leaks into $f$ and $5900 \mathrm{~m}^{3}$ leaks into $\mathrm{m}$. After the 24-h shut-in, the total leak-off ratio reaches $54.2 \%$ and approximately $46.2 \%$ of injected water leaks into the matrix.

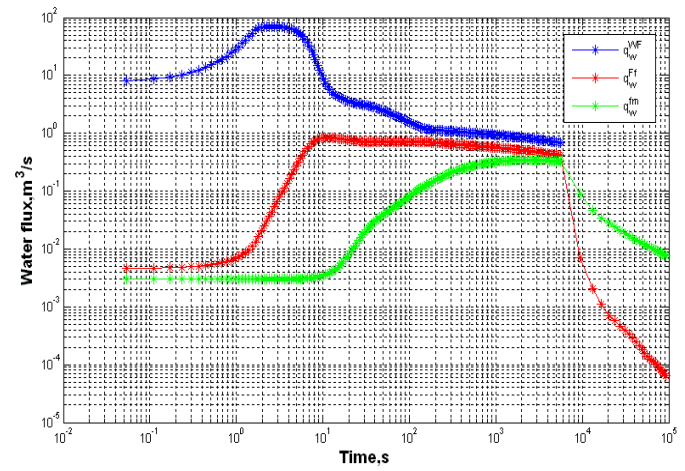

(a)

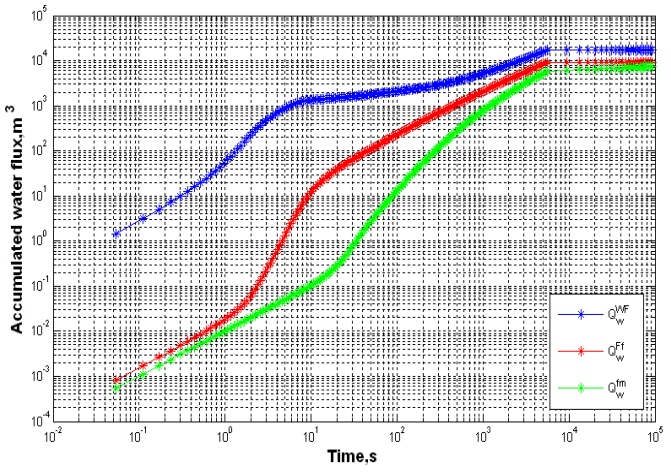

(b)

Figure 6. Comparisons of water fluxes and accumulated fluxes of $W-F, F-f$ and $f-m$. (a) Water fluxes; (b) accumulated water fluxes. 


\subsection{Sensitivity Simulation and Analysis}

To investigate the role of initial reservoir pressure $\left(P_{\mathrm{i}}\right)$, temperature $\left(T_{\mathrm{i}}\right)$, salinity of formation brine $\left(C_{i}{ }^{m}\right)$ and natural-fracture density $\left(n_{\mathrm{f}}\right)$ on water fluxes during the leak-off process of hydraulic fracturing, four group sensitivity simulations have been carried out. One above-mentioned independent variable is changed in each sensitivity simulation while keeping the other variables consistent with the base case. The variation ranges of the four variables is determined according to the geological and construction parameters in Marcellus shale gas basin in the United States $[25,60]$. The results of sensitivity simulation are listed in Table 2.

Table 2. Results of the sensitivity simulation.

\begin{tabular}{lccccccccc}
\hline & Basecase & $\boldsymbol{P}_{\mathbf{i}}=\mathbf{3 0} \mathbf{M P a}$ & $\boldsymbol{P}_{\mathbf{i}}=\mathbf{3 6} \mathbf{M P a}$ & $\boldsymbol{T}_{\mathbf{i}}=\mathbf{3 3 3} \mathbf{K}$ & $\boldsymbol{T}_{\mathbf{i}}=\mathbf{3 4 3} \mathbf{K}$ & $\boldsymbol{C}_{\boldsymbol{i}}{ }^{\boldsymbol{m}}=\mathbf{1 8 0 , 0 0 0}$ & $\boldsymbol{C}_{\boldsymbol{i}}{ }^{\boldsymbol{m}}=\mathbf{1 8 , 0 0 0}$ & $n_{f}=\mathbf{1}$ & $n_{f}=\mathbf{3 0}$ \\
\hline$Q_{w}^{W F}\left(\mathrm{~m}^{3}\right)$ & 17,089 & 12,317 & 7627 & 17,713 & 18,145 & 17,086 & 17,078 & 16,054 & 20,122 \\
$Q_{w}^{F f}\left(\mathrm{~m}^{3}\right)$ & 9209 & 6380 & 3662 & 9561 & 9814 & 9206 & 9199 & 8649 & 10,965 \\
$Q_{w}^{f m}\left(\mathrm{~m}^{3}\right)$ & 5900 & 4086 & 2343 & 6194 & 6399 & 5878 & 5853 & 5542 & 6348 \\
\hline
\end{tabular}

Results indicate that the increase of $P_{\mathrm{i}}$ from $25 \mathrm{MPa}$ to $36 \mathrm{MPa}$ causes the accumulated injection volume from the wellbore to fracture, $Q_{w}^{W F}$, and the accumulated leak-off volume after the water injection, $Q_{w}^{f m}$, to significantly decrease. That indicates the reservoir with higher $P_{i}$ needs higher injection pressure to maintain the injection volume for hydraulic fracturing, although it contributes to reduce the water leak-off. $T_{\mathrm{i}}$ increasing from $323 \mathrm{~K}$ to $343 \mathrm{~K}$ makes the accumulated injection and leak-off volumes evidently increase. That indicates the reservoir with higher $T_{i}$ can contribute to the well injection capacity, but unfortunately it can aggravate the water leak-off as well. $C_{i}^{m}$ decreasing from 280,000 to 18,000 , has non-negligible influence on the injection volume, although it shows obvious influence on the leak-off volume to the matrix. Natural-fracture density increasing from 1 to 30, makes the accumulated injection volume increase by $4068 \mathrm{~m}^{3}$, while the accumulated leak-off volume increases by only $806 \mathrm{~m}^{3}$. That indicates the value of $n_{\mathrm{f}}$ causes less influence on the leak-off volume, but it has a significant influence on the injection volume. Thereafter, for the shale reservoirs with high natural-fracture density, there will be a large amount of injected water storing in dilated natural fractures during the hydraulic fracturing, rather than leaking into the matrix.

\section{Limitations of the Work}

To investigate the influences of hydraulic pressure, natural-fracture dilation, chemical osmosis and thermal osmosis on the leak-off behavior of water during the hydraulic fracturing, coupled thermo-hydro-mechanical-chemical modeling and simulation have been performed. Such work provides an intuitive information of the influence weight of each driving force under given reservoir and fluid conditions. However, there are some limitations of the work. The effect of clay swelling is not considered in this work, although some clays (e.g., smectite) in shale easily swells when in contact with water, and we believe this phenomenon may affect the water leak-off. Precise modeling of various physicochemical phenomena during the treatment of hydraulic fracturing with our leak-off model is considered seriously and will be an important future work.

Besides, it is undeniable that lacking of the model validation with experimental data is another important limitation in this work. Since there are extensive experimental data recently published in the literature, core-scale modeling and simulation of water distribution in the process of leak-off with real experimental data are currently under consideration and will be reported in the future work.

\section{Conclusions}

In this paper, a coupled THMC leak-off model is presented considering the phenomena of natural-fracture dilation, chemical osmosis and thermal osmosis during the leak-off process of hydraulic fracturing. Numerical simulation and sensitivity analysis of water leak-off from a multistage 
fractured horizontal well in a shale gas reservoir are also carried out with THMC model. The main conclusions are as follows:

(1) During the $1.5 \mathrm{~h}$ of fracturing-fluid pumping, water has been leaking from hydraulic fractures to the natural fractures and the matrix, and, during the well shut-in, the leak-off continues. The thermal-osmotic and chemical-osmotic pressures, which are positive driven forces besides the hydraulic pressure difference during the pumping and well shut-in, have aggravated the water leak-off. A multi-field coupled invasion region surrounding the hydraulic fractures in natural fractures and the matrix is created, respectively, during the slickwater injection due to the leak-off mechanism.

(2) After $1.5 \mathrm{~h}$ of water injection, the total injection volume from the wellbore to hydraulic fractures is $17,089 \mathrm{~m}^{3}$, of which approximately $9209 \mathrm{~m}^{3}$ leaks into natural fractures and $5900 \mathrm{~m}^{3}$ leaks into the matrix. After the 24 -h shut-in, the total leak-off ratio reaches $54.2 \%$ and approximately $46.2 \%$ of injected water leaks into the matrix.

(3) The four dominating phenomena, i.e., hydraulic pressure, natural-fracture density, chemical osmosis and thermal osmosis, show various influences on fracturing-fluid leak-off. Among them, the hydraulic pressure has the greatest effect, followed by the temperature-difference-induced thermal osmosis and the salt-concentration-difference-induced chemical osmosis. The natural-fracture density is the weakest factor to the water leak-off under this simulation condition, however, its dilation during the hydraulic fracturing can lead to an extra large amount of injected water, which will be stored inside rather than leaked into the matrix.

(4) Results from this study provide a better understanding of the fluid and heat transport mechanism of water-based fracturing-fluids in shale gas reservoirs. We can infer that a shale gas reservoir with low pressure, high temperature, high salinity and high natural-fracture density is highly absorbent, which leads to the high injection capacity and high leak-off volume.

Acknowledgments: The authors would like to acknowledge the National Natural Science Foundation of China (No.51504266) and Science Foundation of China University of Petroleum, Beijing (No.2462015YQ0212) for their financial support.

Author Contributions: Fei Wang contributed to developing the mathematical model, performed the data analysis, and wrote the manuscript; Baoman Li and Yichi Zhang performed the numerical simulation; Shicheng Zhang supervised the research and edited the manuscript.

Conflicts of Interest: The authors declare no conflicts of interest.

\section{References}

1. Penny, G.S.; Pursley, J.T.; Clawson, T.D. Field study of completion fluids to enhance gas production in the Barnett Shale. In Proceedings of the SPE Gas Technology Symposium, Calgary, AB, Canada, 15-17 May 2006. Paper 100434-MS.

2. Zhong, H. Flow of gas and water in hydraulically fractured shale gas reservoirs. In Proceedings of the EPA HF Workshop, Arlington, VA, USA, 28-29 March 2011.

3. Roychaudhuri, B.; Tsotsis, T.T.; Jessen, K. An Experimental and Numerical Investigation of Spontaneous Imbibition in Gas Shales. In Proceedings of the SPE Annual Technical Conference and Exhibition, Denver, CO, USA, 30 October-2 November 2011.

4. Dehghanpour, H.; Zubair, H.A.; Chhabra, A.; Ullah, A. Liquid Intake of Organic Shales. Energy Fuels 2012, 26, 5750-5758. [CrossRef]

5. Makhanov, K.; Dehghanpour, H.; Kuru, E. An Experimental Study of Spontaneous Imbibition in Horn River Shales. In Proceedings of the SPE Canadian Unconventional Resources Conference, Calgary, AB, Canada, 30 October-1 November 2012.

6. Dehghanpour, H.; Lan, Q.; Saeed, Y.; Fei, H.; Qi, Z. Spontaneous Imbibition of Brine and Oil in Gas Shales: Effect of Water Adsorption and Resulting Microfractures. Energy Fuels 2013, 27, 3039-3049. [CrossRef] 
7. Lan, Q.; Ghanbari, E.; Dehghanpour, H.; Hawkes, R. Water Loss versus Soaking Time: Spontaneous Imbibition in Tight Rocks. In Proceedings of the SPE/EAGE European Unconventional Conference and Exhibition, Vienna, Austria, 25-27 February 2014.

8. Fan, Y.; Economides, M.J. Fracturing Fluid Leakoffand Net Pressure Behavior in Frac \& Pack Stimulation. In Proceedings of the International Meeting on Petroleum Engineering, Beijing, China, 14-17 November 1995.

9. Ehlig-Economides, C.A.; Economides, M.J. Water as Proppant. In Proceedings of the SPE Annual Technical Conference and Exhibition, Denver, CO, USA, 30 October-2 November 2011.

10. Sharma, M.; Agrawal, S. Impact of Liquid Loading in Hydraulic Fractures on Well Productivity. In Proceedings of the SPE Hydraulic Fracturing Technology Conference, Woodlands, TX, USA, 4-6 February 2013.

11. Williams, B.B. Fluid loss from hydraulically induced fractures. J. Pet. Technol. 1970, 22, 882-888. [CrossRef]

12. Meyer, B.R.; Jacot, R.H. Implementation of Fracture Calibration Equations for Pressure Dependent Leakoff. In Proceedings of the SPE/AAPG Western Regional Meeting, Long Beach, CA, USA, 19-22 June 2000.

13. Yew, C.H.; Ma, M.J.; Hill, A.D. A Study of Fluid Leakoff in Hydraulic Fracture Propagation. In Proceedings of the International Oil and Gas Conference and Exhibition, Beijing, China, 7-10 November 2000.

14. Li, Y.; Guo, J.; Zhao, J. A New Model of Fluid Leakoff in Naturally Fractured Gas Fields and its Effects on Fracture Geometry. In Proceedings of the Canadian International Petroleum Conference, Calgary, AB, Canada, 7-9 June 2005.

15. Michel, G.; Sigal, R.F.; Civan, F.; Devegowda, D. Effect of Capillary Relaxation on Water Entrapment after Hydraulic Fracturing Stimulation. In Proceedings of the Americas Unconventional Resources Conference, Pittsburgh, PA, USA, 5-7 June 2012.

16. Jurus, W.J.; Whitson, C.H.; Golan, M. Modeling Water Flow in Hydraulically-Fractured Shale Wells. In Proceedings of the SPE Annual Technical Conference and Exhibition, New Orleans, LA, USA, 30 September-2 October 2013.

17. Xu, Y.; Fu, Y.; Ezulike, D.O. Modeling Two-Phase Flowback Data Using an Open Tank Model. In Proceedings of the SPE/CSUR Unconventional Resources Conference, Calgary, AB, Canada, 20-22 October 2015.

18. Zoback, M.D.; Kohli, A.; Das, K.; McClure, M. The Importance of Slow Slip on Faults during Hydraulic Fracturing Stimulation of Shale Gas Reservoirs. In Proceedings of the SPE Americas Unconventional Resources Conference, Richardson, TX, USA, 5-7 June 2012.

19. Weng, X.; Sesetty, V.; Kresse, O. Investigation of Shear-Induced Permeability in Unconventional Reservoirs. In Proceedings of the 49th US Rock Mechanics/Geomechanics Symposium, San Francisco, CA, USA, 28 June-1 July 2015.

20. Maxwell, S.C.; Mack, M.; Zhang, D.; Chorney, D.; Goodfellow, S.D. Differentiating Wet and Dry Microseismic EventsInduced during Hydraulic Fracturing. In Proceedings of the Unconventional Resources Technology Conference, San Antonio, TX, USA, 20-22 July 2015.

21. Bredehoeft, J.D.; Blyth, C.R.; White, W.A.; Maxey, G.B. Possible Mechanism for concentration of Brine in Subsurface Formations. AAPG Bull. 1963, 47, 257-269.

22. Schimmelmann, A.; Boudou, J.P.; Lewan, M.D. Experimental Controls on D/H and C13/C12 Ratios of Kerogen, Bitumen and Oil during Hydrous Pyrolysis. Org. Geochem. 2001, 32, 1009-1018. [CrossRef]

23. Mastalerz, M.; Schimmelmann, A. Isotopically Exchangeable Organic Hydrogen in Coal Relates to Thermal Maturity and Maceral Composition. Org. Geochem. 2002, 33, 921-931. [CrossRef]

24. Fang, C.; Huang, Z.; Wang, Q. Rich-gas Shale Reservoirs Ultra-low Water Saturation Causes and Significance. Nat. Gas Geosci. 2014, 25, 471-476.

25. Haluszczak, L.O.; Rose, A.W.; Kump, L.R. Geochemical Evaluation of Flowback Brine from Marcellus Gas Wells in Pennsylvania, USA. Appl. Geochem. 2012, 28, 55-61. [CrossRef]

26. Fakcharoenphol, P.; Kurtoglu, B.; Charoenwongsa, S.; Wu, Y.S. The Effect of Osmotic Pressure on Improve Oil Recovery from Fractured Shale Formations. In Proceedings of the SPE Unconventional Resources Conference, The Woodlands, TX, USA, 1-3 April 2014.

27. Lomba, E.F.T.; Chenevert, M.E.; Sharma, M.M. The role of osmotic effects in fluid flow through shales. J. Pet. Sci. Eng. 2000, 25, 25-35. [CrossRef]

28. Rahman, M.M.; Chen, Z.; Rahman, S.S. Experimental Investigation of Shale Membrane Behavior under Tri-Axial Condition. Pet. Sci. Technol. 2005, 23, 1265-1282. [CrossRef] 
29. Wang, J.J.; Rahman, S.S. An Investigation of Fluid Leak-off Due to Osmotic and Capillary Effects and Its Impact on Micro-Fracture Generation during Hydraulic Fracturing Stimulation of Gas Shale. In Proceedings of the EUROPEC, Madrid, Spain, 1-4 June 2015.

30. Fakcharoenphol, P.; Torcuk, M.; Kazemi, H.; Wu, Y.S. Effect of shut-in time on gas flow rate in hydraulic fractured shale reservoirs. J. Pet. Sci. Eng. 2015, 32, 109-121. [CrossRef]

31. Wang, F.; Pan, Z.; Lin, H.; Zhang, S. A Chemical Potential Dominated Model for Fracturing-Fluid Flowback Simulation in Hydraulically Fractured Gas Shale. In Proceedings of the SPE Annual Technical Conference and Exhibition, Dubai, UAE, 26-28 September 2016.

32. Li, X.; Abass, H.; Teklu, T.W. A Shale Matrix Imbibition Model-Interplay between Capillary Pressure and Osmotic Pressure. In Proceedings of the SPE Annual Technical Conference and Exhibition, Dubai, UAE, 26-28 September 2016.

33. Dirksen, D. Thermo-osmosis through compacted saturated clay membranes. Soil Sci. Soc. Am. Proc. 1969, 33, 821-826. [CrossRef]

34. Ghassemi, A.; Diek, A. Porothemoelasticity for swelling shales. J. Pet. Sci. Eng. 2002, 34, 123-135. [CrossRef]

35. Zheng, L.; Samper, J.; Montenegro, L. A coupled THC model of the FEBEX in Situ Test with Bentonite Swelling and Chemical and Thermal Osmosis. J. Contam. Hydrol. 2011, 126, 45-60. [CrossRef] [PubMed]

36. Eshkalak, M.O.; Aybar, U.; Sepehrnoori, K. An Integrated Reservoir Model for Unconventional Resources, Coupling Pressure Dependent Phenomena. In Proceedings of the SPE Eastern Regional Meeting, Charleston, WV, USA, 21-23 October 2014.

37. Wang, F.; Pan, Z.; Zhang, S. Modeling Water Leak-off Behavior in Hydraulically Fractured Gas Shale under Multi-mechanism Dominated Conditions. Transp. Porous Media 2017, 118, 177-200. [CrossRef]

38. Han, D.; Gao, Z.; Gao, P. Physical Chemistry; Higher Education Press: Beijing, China, 2009.

39. Chen, F.; Wei, M.; Ye, Y.; Yuan, W. Calculation of Chemical Potential in Dilute Solution and Derivation of the Osmosis Pressure Equation. Univ. Chem. 2015, 30, 63-67.

40. Oort, E.V.; Hale, A.H.; Mody, F.K.; Roy, S. Transport in Shales and the Design of Improved Water-Based Shale Drilling Fluids. SPE Drill. Complet. 1996, 11, 137-146. [CrossRef]

41. Ewy, R.T.; Stankovich, R.J. Pore Pressure Change Due to Shale-Fluid Interactions: Measurements under Simulated Wellbore Conditions. In Proceedings of the Pacific Rocks 2000, Fourth North American Rock Mechanics Symposium, Seattle, WA, USA, 31 July-3 August 2000; pp. 147-154.

42. Mody, F.K.; Tare, U.A.; Tan, C.P.; Drummond, C.J.; Wu, B. Development of Novel Membrane Efficient Water-Based Drilling Fluids through Fundamental Understanding of Osmotic Membrane Generation in Shales. In Proceedings of the SPE Annual Technical Conference and Exhibition, San Antonio, TX, USA, 29 September-2 October 2002.

43. Schlemmer, R.; Friedheim, J.E.; Growcock, F.B.; Bloys, J.B.; Headley, J.A. Chemical Osmosis, Shale, and Drilling Fluids. SPE Drill. Complet. 2003, 18, 318-331. [CrossRef]

44. McTigue, D.F. Thermoelastic Response of Fluid-saturated Porous Rock. J. Geophys. Res. 1986, 91, $9533-9542$. [CrossRef]

45. Winterfeld, P.H.; Wu, Y. Simulation of Coupled Thermal-Hydrological-Mechanical Phenomena in Porous and Fractured Media. SPE J. 2016, 21, 1041-1049. [CrossRef]

46. McLennan, J.; Potocki, D. Hydraulic Fracturing Complexity: Interaction between Hydraulic and Natural Fractures. In Proceedings of the AAPG Workshop: Geomechanics and Reservoir Characterization of Shales and Carbonates, Baltimore, MD, USA, 16-17 July 2013.

47. Tang, H.; Killough, J.E.; Heidari, Z.; Sun, Z. A New Technique To Characterize Fracture Density by Use of Neutron Porosity Logs Enhanced by Electrically Transported Contrast Agents. In Proceedings of the SPE Annual Technical Conference and Exhibition, Dubai, UAE, 26-28 September 2016.

48. Biot, M.A.; Willis, D.G. The Elastic Coefficients of the Theory of Consolidation. J. Appl. Mech. 1957, 15, 594-601.

49. Bybee, K. Non-Darcy Flow in Hydraulic Fractures. J. Pet. Technol. 2006, 58, 58-59. [CrossRef]

50. Bian, X.; Zhang, S.; Zhang, J.; Wang, F. A New Method to Optimize the Fracture Geometry of a Frac-packed Well in Unconsolidated Sandstone Heavily Oil Reservoirs. Sci. China Technol. Sci. 2012, 55, 1725-1731. [CrossRef]

51. Kazemi, H.; Gilmanc, J.R.; Elsharkawy, A.M. Analytical and Numerical Solution of Oil Recovery from Fractured Reservoirs with Empirical Transfer Functions. SPE Reserv. Eng. 1992, 7, 219-227. [CrossRef] 
52. Silin, D.; Kneafsey, T.J. Shale Gas: Nanometer-Scale Observations and Well Modeling. J. Can. Pet. Technol. 2012, 51, 464-475. [CrossRef]

53. Gilman, J.R. Practical Aspects of Simulation of Fractured Reservoirs. In Proceedings of the International Forum on Reservoir Simulation, Buhl, Germany, 23-27 June 2003.

54. Yan, B.; Mi, L.; Wang, Y. Mechanistic Simulation Workflow in Shale Gas Reservoirs. In Proceedings of the SPE Reservoir Simulation Conference, Montgomery, TX, USA, 20-22 February 2017.

55. Lee, M. Modified Biot-Gassmann theory for calculating elastic velocities for unconsolidated and consolidated sediments. Mar. Geophys. Res. 2002, 23, 403-412. [CrossRef]

56. Chen, Z.; Xue, C.; Jiang, T.; Qin, Y. Proposals for the Application of Fracturing by Stimulated Reservoir Volume (SRV) in Shale Gas Wells in China. Nat. Gas Ind. 2010, 30, 30-32.

57. Garavito, A.M.; Kooi, H.; Neuzil, C.E. Numerical modeling of a long-term in situ chemical osmosis experiment in the Pierre Shale, South Dakota. Adv. Water Resour. 2006, 29, 481-492. [CrossRef]

58. Ghassemi, A.; Tao, Q.; Diek, A. Influence of coupled chemo-poro-thermoelastic processes on pore pressure and stress distributions around a wellbore in swelling shale. J. Pet. Eng. 2009, 67, 57-64. [CrossRef]

59. Gdanski, R.D.; Fulton, D.D.; Chen, C. Fracture-Face-Skin Evolution during Cleanup. SPE Prod. Oper. 2009, 24, 22-34. [CrossRef]

60. Zhang, D.; Yang, T. Environmental impacts of hydraulic fracturing in shale gas development in the United States. Pet. Explor. Dev. 2015, 42, 801-807. [CrossRef]

(C) 2017 by the authors. Licensee MDPI, Basel, Switzerland. This article is an open access article distributed under the terms and conditions of the Creative Commons Attribution (CC BY) license (http://creativecommons.org/licenses/by/4.0/). 